\title{
The Relationship between Role Clarity and Efficiency of Employees in Management \& Resource Development Department of Ministry of Health and Medical Education of I.R.Iran, 2014
}

\author{
Fatemeh Samie $^{1}$, Leila Riahi ${ }^{2}$ and Seyed Jamaledin Tabibi ${ }^{3}$ \\ ${ }^{1}$ M.Sc. Student, Department of Health Services Management, Science and Research Branch, Islamic \\ Azad University, Tehran, Iran. \\ ${ }^{2}$ Assistant professor, Department of Health Services Management, Science and Research Branch, \\ Islamic Azad University (IAU),Tehran,Iran \\ ${ }^{3}$ Professor, Department of Health Services Management, Science and Research Branch, \\ Islamic Azad University (IAU),Tehran,Iran.
}

DOI: http://dx.doi.org/10.13005/bbra/1964

(Received: 14 July 2015; accepted: 09 October 2015)

\begin{abstract}
The occupational roles of employees have been a challenging subject among the scholars and researchers during the recent years. The first step to evaluate the performance of the sections of an organization is to evaluate their efficiency. Therefore, the main aim of this research is to investigate the relationship of the role clarity and the efficiency of the employees of Management \& Resources Development Department of the Ministry of Health and Medical Education of I.R.Iran. This is a descriptive-analytical research conducted in a certain period in 2014 on 133 sample employees selected randomly using Cochran's C test from an statistical society of 312 employees of Management \& Resources Development Department of the Ministry of Health and Medical Education of I.R.Iran. The questionnaire was created by the researcher and, having determined its reliability and validity, was distributed among the employees and collected. Since the variables were normal, the T Test and Analysis of Variance were used to investigate the significance of the differences of role clarity and efficiency variables and also to investigate the relationship between the role clarity and factors of efficiency. Most of the employees in this study were female (63.9\%), holders of Master's degrees $(40.6 \%)$. The most average of the surveyed variables belonged to role clarity $(2.47)$ and the least average accounted for educational aspect (1.66) among the employees. There was a significant statistical relationship between role clarity and general efficiency of the employees ( $p$-value $=0.000$ ), and between the role clarity and each aspects of efficiency of employees including alignment with organizational goals, work pace, proper use of the equipment and facilities, selfassessment, trainings, being committed to the workplace regulations. There is a significant and direct relationship between the role clarity and the efficiency of the employees. Therefore, the managers of Ministry of Health and Medical Education are suggested to aim their efforts to increase the role clarity to create a more proper ground for the efficiency of the works.
\end{abstract}

Keywords: Role clarity, Efficiency, Ministry of Health and Medical Education.

The occupational roles of employees have been a challenging issue for researchers and

\footnotetext{
* To whom all correspondence should be addressed. Te.l: 09121131901;

E-mail:l.riahi@srbiau.ac.ir
}

scholar in recent years ${ }^{1}$. Role clarity is one of the important issues which should get clear for staff when they are employed. In other words, what responsibilities the employees will have should be clear for them at the outset. In fact, it helps employees analyze the conditions to see whether 
it is possible for them to start the job or not. If we do not give enough information to employees and expect them to work based on our expectations, they will not be able to deal with new challenges². Researchers believe that if goals are clear for employees, they know why and how work to achieve them ${ }^{3}$.

Employees should be given enough information to know how to deal with new challenges and perform the expected tasks. In other words, lack of information on effective career goals and behaviors can result in ineffective and insufficient effort to perform the tasks, in turn, decreasing the job performance ${ }^{4-6}$ and damaging the role, potentially ${ }^{7}$. Furthermore, according to the theory of role, high ambiguity may cause the employee to abandon effort or use defensive mechanisms to distort job facts ${ }^{8}$. Employees with unclear role expectations are reluctant and have no initiative in doing the work. Ambiguity makes employees believe that they need support; thus, they feel they are ineffective in work environment ${ }^{9}$. As a result, if employee's work roles are not managed efficiently, job dissatisfaction, lower levels of commitment and efficiency and more resigns will be resulted ${ }^{1}$.

Since roles pay attention to employees' expectations and behaviors related to the job and act as a border between the employee and organization, employees would rather work in clear environments where they are given enough information about their responsibilities ${ }^{8}$ and it will include better performance of employees in fulfilling the tasks and responsibilities ${ }^{10}$. Moreover, employees who have clear work aims and know how to achieve them, feel more effective in working environments. High levels of role clarity enables employees to present strategies and solutions to perform the assigned tasks more effectively ${ }^{11}$; therefore, they make more effective decisions ${ }^{12}$.

On the other hand, the first step to be taken in analyzing the performance of various sectors of health care is evaluating the performance $^{13}$. In other words, one of the components which should be considered in the performance of employee and organization, is performance. Performance may include performing a series of operations resulting in achieving aims effectively in such a way that time, capital and talent can be used completely. Thus, a successful manager can take measures to both help themselves achieve the goals and take advantage in applying resources ${ }^{14}$. All in all, performance can be evaluated through recognizing effective components in performance. A capable manager can help the organization get out of ambiguity and dilemma using human and financial resources of organization to achieve the goals ${ }^{15}$.

The present research is aimed at examining the relationship between role clarity and performance of the employees of Management \& Resources Development Department of the Ministry of Health and Medical Education of Iran as well as analyzing the relationship between role clarity and performance components including: alignment of performance and organizational goals, work pace, the use of equipment and facilities, selfassessment, training, being commitment to the workplace regulations of employees working for Deputy of Management and Resource Development of the headquarters of the Ministry of Health and Medical Education as a policymaking body for its sub-units.

\section{Review of the Related Literature}

In a study carried out by Kauppila (2014) titled as "So, What Am I Supposed to Do?" a multilevel examination of role clarity was done on 848 employees and 25 managers in 25 organizations in Finland. This study examined effects of internal work locus of control, general self-efficacy, and leader-member exchange on role clarity. Having been analyzed the collected multi-level data, it was turned out that a deliberate strategy-making pattern negatively moderates the relationship between general self-efficacy and role clarity ${ }^{16}$.

In a review study titled as "the importance of role clarification in workgroups: Effects on perceived role clarity, Work satisfaction, and turnover rates" Hassan (2013) concluded that offices with high levels of role clarity have the significantly higher levels of job satisfaction and lower rates of change ${ }^{17}$.

Yet, in another study titled as "the effect of service employees, perception of role clarity and psychological empowerment on organizational commitment, job satisfaction and staying intention” Furenes (2011) examined the mentioned issue in three hotels, IT and bank industries. The results showed that there were different interpretations of role clarity and psychological 
empowerment among the mentioned industries. Furthermore, it was turned out that empowerment had a significant effect on attitudes and approaches, while role clarity had an insignificant effect. Empowerment, anyway, had a moderating effect (as a moderating variable) in relationship between role clarity and attitudes-results-job satisfaction, organizational commitment and staying intention ${ }^{18}$.

Furthermore, in another study carried out by Hassanzadeh, Rajaeipour and Noori, (2013) titled as "role clarity and psychological empowerment" among all employees of Golestan Province Gas Company, the measurement tool including two psychological empowerment questionnaires developed based on Spreitzer' psychological empowerment theory and role clarity questionnaire developed based on Sawyer's theory. Results showed that there was a significant positive correlation between role clarity and employees' psychological empowerment ${ }^{19}$.

Moreover, Rajaeipour and Bahrami (2008) carried out a study titled as "the relationship between role clarity and job commitment of the employees of the schools of Isfahan University of Medical Sciences" on 144 employees as sample of the research. Results showed that the employees' mean scores were higher than the average and that there was a positive significant relationship between those two. Furthermore, it was turned out that there was a positive significant relationship between role clarity and all four job commitments dimensions (professional dependency, organizational dependency, commitment to work values and job contribution $)^{20}$.

Mukherjee and Malhotra (2006)

Table 1. Cronbach's Alpha Coefficient and the Correlation Coefficient ICC among Staff under Study at Ministry of Health, Deputy of Development

\begin{tabular}{lccc}
\hline Questions & $\begin{array}{c}\text { Number of } \\
\text { Categories }\end{array}$ & $\begin{array}{c}\text { Cronbach's Alpha } \\
\text { Coefficient }\end{array}$ & $\begin{array}{c}\text { (Confidence Interval) } \\
\text { ICC }\end{array}$ \\
\hline $\begin{array}{l}\text { Performance Alignment with } \\
\text { Organizational Goals }\end{array}$ & 11 & 0.90 & $0.91(0.95,0.84)$ \\
$\begin{array}{l}\text { Work Pace } \\
\text { The Use of Equipment and }\end{array}$ & 7 & 0.60 & $0.71(0.84,0.45)$ \\
Facilities & 5 & 0.81 & $0.80(0.89,0.63)$ \\
Training & 8 & 0.77 & $0.88(0.93,0.78)$ \\
$\begin{array}{l}\text { Being Commitment to the } \\
\text { Workplace Regulations }\end{array}$ & 8 & 0.86 & $0.87(0.93,0.76)$ \\
Self-assessment & 16 & 0.95 & $0.88(0.93,0.77)$ \\
Role Clarity & 37 & 0.94 & $0.95(0.97,0.91)$ \\
Efficiency & 55 & 0.96 & $0.94(0.97,0.89)$ \\
\hline
\end{tabular}

Table 2. Statistical Summary of Scores Given to Different Dimensions of the Questionnaire among Staff under Study at Ministry of Health, Deputy of Development

\begin{tabular}{|c|c|c|c|c|c|}
\hline Variable & Mean & Median & Standard Deviation (SD) & Minimum & Maximum \\
\hline \multicolumn{6}{|l|}{ Performance Alignment } \\
\hline with Organizational Goals & 2.11 & 2.09 & 0.05 & 0.55 & 3.55 \\
\hline Work Pace & 1.93 & 2 & 0.04 & 0.29 & 3.43 \\
\hline \multicolumn{6}{|l|}{ The Use of Equipment } \\
\hline Training & 1.66 & 1.62 & 0.05 & 0.38 & 3.62 \\
\hline \multicolumn{6}{|l|}{ Being Commitment to the } \\
\hline Workplace Regulations & 2.30 & 2.37 & 0.05 & 0 & 3.62 \\
\hline Self-assessment & 1.93 & 1.93 & 1.06 & 0 & 3.62 \\
\hline Efficiency & 1.98 & 1.98 & 0.04 & 0.78 & 3.16 \\
\hline Role Clarity & 2.47 & 2.41 & 0.05 & 1.16 & 3.95 \\
\hline
\end{tabular}


conducted a study under the title of "does role clarity explain employee-perceived service quality? A study of antecedents and consequences in call centres?" in a commercial bank in Golestan. Results showed that the quality of role, played a significant role in explaining employees' perception of quality of services. Furthermore, it was turned out that the feedback and team cooperation considered as key antecedents of role clarity affected the role clarity significantly in turn, affecting job satisfaction and organizational commitments which were regarded as key consequences of role ${ }^{21}$.

In a study conducted by Klein et al., (2006) on newly hired employees in a large US educational institution, it was turned out that newly-employed staff should be fully aware of the factors related to their jobs to be able to achieve the job satisfaction and organizational commitment to examine socializing of new employees ${ }^{22}$.

In a study conducted by Lyons (2004) on 156 of University of Michigan School of Nursing staff, it was turned out that there was a direct relationship between role clarity, job satisfaction and at last job commitment ${ }^{23}$.
Furthermore, Bray and Brawley (2002) carried out another study titled as "role efficacy, role clarity, and role performance effectiveness". The results of their study showed that employees with higher role clarity were much more effective and performed much better than those with lower level of role clarity ${ }^{24}$.

Mcenrue (1984) conducted a study on 304 employees of operational managers of the University of California and found that there was a positive relationship between role clarity and job performance. Results also showed that when there was a role ambiguity, employees' performance would not be effective enough ${ }^{25}$.

Paslari and Bagheri (2014) carried out another study titled as "study of Intellectual Capital and it's relation with efficiency of organization employee (Case Study of Melli Bank Branches in Bandar Abbass)" on 173 employees using a questionnaire. Results showed that there was a significant relationship between human's capital, social capital, structural capital and performance of employees ${ }^{26}$.

Bagherpour, Koohestani and Karshekani

Table 3. Statistical Summary Scores Given to Different Variables under Study among Staff in Separation of Sex

\begin{tabular}{llllll}
\hline \multirow{2}{*}{ Variable } & \multicolumn{2}{c}{ Women Staff } & & \multicolumn{2}{c}{ Men Staff } \\
\cline { 2 - 3 } \cline { 5 - 6 } & Mean & SD & & Mean & SD \\
\hline Performance Alignment with Organizational Goals & 2.07 & 0.07 & & 2.18 & 0.08 \\
Work Pace & 1.89 & 0.05 & & 1.99 & 0.08 \\
The Use of Equipment and Facilities & 1.89 & 0.06 & & 2.04 & 0.10 \\
Training & 1.65 & 0.06 & & 1.67 & 0.09 \\
Being Commitment to the Workplace Regulations & 2.29 & 0.06 & & 2.29 & 0.11 \\
Self-assessment & 1.92 & 0.07 & & 1.95 & 0.10 \\
Efficiency & 1.96 & 0.05 & & 2.02 & 0.07 \\
Role Clarity & 2.43 & 0.06 & & 2.55 & 0.07 \\
\hline
\end{tabular}

Table 4. Pearson Correlation Coefficient Test for Determining the Relationship between Role Clarity and its Components among Staff under Study

\begin{tabular}{|c|c|c|c|}
\hline & Variable & $\mathrm{R}$ & P-Value \\
\hline \multirow[t]{7}{*}{ Role Clarity } & Performance Alignment with Organizational Goals & 0.52 & 0.000 \\
\hline & Work Pace & 0.40 & 0.000 \\
\hline & The Use of Equipment and Facilities & 0.52 & 0.000 \\
\hline & Training & 0.45 & 0.000 \\
\hline & Being Commitment to the Workplace Regulations & 0.21 & 0.017 \\
\hline & Self-assessment & 0.38 & 0.000 \\
\hline & Efficiency & 0.49 & 0.000 \\
\hline
\end{tabular}


(2012) carried out another study titled as "an investigation of relationship of the work life quality and the efficiency of the Employees of Education Department" on 160 staff of Education Department of Kashmar, Khalil Abad, Bordsekan and Koohsorkh. Two questionnaires of work life quality (Bolhari et al. 2010) and performance (Hosseini, 2009) were used. Results showed that 1 : there was a positive significant relationship between work life and employees' performance ${ }^{27}$.

Jafari, Eivazadeh and Moeinian (2011) conducted another study on 100 of employees of Islamic Azad University of Tehran, Ghiamdasht branch. Results showed that there was a significant relationship between managers' performance and employees' job stress ${ }^{28}$.

Azadvari, (2010) conducted a study titled as "investigation of the level of efficiency of the women's Police Department of Mashahd” on 112 managers and commanders of Police Command Headquarters of Khorasan Razavi, commanders and staff of Police headquarters of Samen and heads of women police agencies of Mashhad randomly. Results showed that level of efficiency of the women's Police Department of Mashhad was in much better situation in terms of speed, accuracy, rectitude, motivation and responsibility ${ }^{29}$.

\section{Type of Research}

It is a cross-sectional descriptive-analytic research carried out in 2014.

\section{Participants}

The participants of this study were 312 staff working in Management \& Resources Development Department of the Ministry of Health and Medical Education of I.R.Iran.

\section{Research Sample and Sampling Method}

The sample under study was 123 employees determined based on Cochran's formula, with error level of 5\%. Simple random sampling was used in this research and in order to achieve the minimum sample required for the research (123), 140 questionnaires were distributed randomly among staff working in the Management \& Resources Development Department of the Ministry of Health and Medical Education of Iran, of which 7 questionnaires were excluded due to some lost data; therefore, the sample size was reduced to 133 samples on which the final analysis was carried out.

\section{Data Collection and Instrumentation}

Data was collected by use of questionnaire. Two questionnaires of role clarity and efficiency developed by the researcher were used. The first questionnaire included 37 questions and the second one had 55 questions in 6 performance alignment with organizational goals, work pace, use of equipment and facilities, training, being commitment to the workplace regulations and self-assessment dimensions, both of which were prepared based on 5-point Likert scale. In order to calculate scores, considering the fact that each question was given a sore from zero to four, the scores given to questions were summed up and the average score was calculated. It is also worth mentioning that demographic information in this research including age, sex, marital status, type of employment, work experience, job category, level of education, and position were collected as well.

The Validity and Reliability of Instrumentation

In order to verify the reliability and validity of questionnaire content, the researcher used ten experts' opinions. The mentioned questionnaire was distributed among experts, specialists and some participants to evaluate the formal validity including formal validity, phrasing, and content of questions. Furthermore, in order to analyze the consistency of the mentioned questionnaire, the test-retest method was used and in order to determine the test-retest reliability coefficient, 40 participants were selected randomly from the sample and questionnaires were distributed among them and then collected. Then, one week later, the same questionnaires were distributed again among the same participants and then collected. Once the questionnaires were collected, the correlation coefficient between scores was calculated and the test-retest was calculated for each factor (coefficient ICC). To assess the internal consistency of the scale, Cronbach's alpha coefficient was calculated for each factor and for the whole efficiency and role clarity questionnaire. The result was satisfactory. Table (1) shows the results.

\section{The Analysis of Research Findings}

The considered variables were attained using raw data available in the questionnaire. Data was analyzed by computer through SPSS version 18 and EXCEL in both descriptive and inferential 
statistics sections. Before analysis, KolmogorovSmirnov test was performed to test the normality of data. Once the normality of variables was achieved and approved, Pearson correlation test was applied to examine and analyze the relationship between role clarity variable and secondary variables of performance alignment with organizational goals, work pace, the use of equipment and facilities, self-assessment, training, being commitment to the workplace regulations. Furthermore the researcher used the same test to analyze the relationship between role clarity variable and efficiency variable.

\section{Descriptive Statistics \\ Demographic Information}

Participants of the study included: $63.9 \%$ women, $74.4 \%$ married, $40.6 \%$ holders of master's degrees, approximately 33\% aged 31-35, 36.8\% with 6-10 years of job experience, $41.4 \%$ payment clerk, $55 \%$ working in finance and administrative fields and $51.1 \%$ were experts.

Table (2) shows a statistical summary of variables under study among participants. According to the table, the mean score of role clarity variable (mean score: 2.47, SD: 0.05 ) was higher than means of other variables among participants. The maximum (highest) mean score accounted for being commitment to the workplace regulations dimension (means core: 2.30, SD: 0.05) and the minimum (lowest) mean score accounted for the training dimension (mean score: 1.66; SD: 0.05 ) among staff under study.

Table (3) indicates means of variables under study in separation of sex. As observed, the mean scores are higher for men employees than the women in all variables except in being committed to the workplace regulations variable.

Regarding the fact that the scores of role clarity and different dimensions of efficiency are between $0-4$, the score less than 1.5 accounted for variable score at low level, between 1.5 - 2.5 at average level and over 2.5 at high level. Results showed that efficiency and role clarity scores were at average level among all participants.

\section{Inferential Statistics \\ Research Hypotheses}

The First Hypothesis

There is a significant relationship between role clarity variable and performance alignment with organizational goals of staff at Ministry of Health and Education, Deputy of Development.

\section{The Second Hypothesis}

There is a significant relationship between role clarity and work pace t of staff at Ministry of Health and Education, Deputy of Development.

\section{The Third Hypothesis}

There is a significant relationship between role clarity and the use of equipment and facilities of staff at Ministry of Health and Education, Deputy of Development.

\section{The Fourth Hypothesis}

There is a significant relationship between role clarity and training of staff at Ministry of Health and Education, Deputy of Development. The Fifth Hypothesis

There is a significant relationship between role clarity and being commitment to the workplace regulations of staff at Ministry of Health and Education, Deputy of Development.

\section{The Sixth Hypothesis}

There is a significant relationship between role clarity and self-assessment of staff at Ministry of Health and Education, Deputy of Development.

\section{The Seventh Hypothesis}

There is a significant relationship between role clarity and efficiency of staff at Ministry of Health and Education, Deputy of Development.

Table (4) illustrates Pearson correlation coefficient to determine the relationship between role clarity and efficiency and the components among staff under study. As shown in the table, positive (Pearson) correlation coefficient of role clarity with performance alignment with organizational goals (0.52), work pace $(0.40)$, the use of equipment and facilities (0.52), training (0.45), being commitment to the workplace regulations (0.21), self-assessment (0.38), efficiency (0.49) among staff under study indicated a significant relationship between role clarity and the above-mentioned components. In other words, if role clarity increases, performance alignment with organizational goals, work pace, the use of equipment and facilities, training, being commitment to the workplace regulations, selfassessment and efficiency increase in organization and vice versa. Furthermore, regarding the $\mathrm{p}$-value obtained (p-value $<0.05$ ) for role clarity relationship with the above-mentioned variables among staff under study, it can be stated that there is a significant relationship between role clarity and 
performance alignment with organizational goals, work pace, the use of equipment and facilities, training, being commitment to the workplace regulations, self-assessment and efficiency in terms of statistics. It fact, such a significant relationship means all research hypotheses have been accepted.

\section{DISCUSSION}

Organizations need specialists with high efficiency to survive ${ }^{30}$. Ministry of Health, the policy-maker body, uses experienced skilled staff to advocate rights and meet the health needs of society ${ }^{31}$. Role clarity can cause job satisfaction in turn creating encouragement and satisfaction in employees. Such a feeling finally results in increasing staff's efficiency. Healy (1983) carried out a study in this regard and showed that if employees' responsibilities and roles are clear in an organization, they show better performance and efficiency because employees have enough information of organization expectations and they know about solutions and strategies to increase and improve ability to perform tasks much more efficiently (32). Therefore, if employees know what they are expected to do, they can be more innovative and creative in performing tasks and fulfilling responsibilities. The results of the present research showed that there was a direct and significant relationship between role clarity and employees' efficiency. In order words, if role clarity increases, efficiency increases as well. In Azadvari's study (2010), efficiency variable mean was 3.44 while it was 1.98 in the present research which was due to the low score of training, work pace and self-assessment dimensions among employees under study. Azadvari examined efficiency, work pace, and accuracy of performance in her study and showed that employees had more efficiency and accuracy of performance in fulfilling their own responsibilities ${ }^{29}$. In the present research, Ministry of Health staff took the advantage of an acceptable level of performance alignment with organizational goals; however, work pace was not considerably high among the staff.

In Rajaeipour and Bahrami's study (2008), the mean score of role clarity was 2.76 and the standard deviation was 0.52 which are close to the mean of the same variable in the present research.
Rajaeipour showed that the correlation between role clarity and job commitment was 0.31 which was less than that of the present research. There was a significant relationship between role clarity and commitment to work values ${ }^{20}$. There was a significant relationship between role clarity and being commitment to the workplace regulations which was consistent with Rajaeipour's study. Furthermore, the highest mean score accounted for being commitment to the workplace regulations which was regarded as the most fundamental principles of every employee's success in any work environments.

Jafari et al. (2011) carried out a study and showed that there was a significant relationship between managers' efficiency and staff's job stress and because of the negative correlation between efficiency and job stress, managers' efficiency reduce if staff's stress increases. In the present study, however, regarding the positive correlation of relationship between efficiency and role clarity, it can be concluded that Ministry of Health employees' efficiency will increase if their role clarity increases ${ }^{28}$.

In another study carried out by Mcenrue (1984) in California University on 340 operational managers, it was found out that there was a significant and direct relationship between role clarity and job performance ${ }^{25}$ which was in line with the present research results.

Laudon and Price (2000) and Sibley (1977) showed that applying information technology (IT) in optimal, effective and efficient use of financial and human resources, reducing duration of the work, access to timely, accurate, effective and correct information, reducing of costs and mistakes ${ }^{33-34}$. Using equipment and facilities which were dimensions of efficiency accounted for low scores among employees under study in the present research. In this regard, managers need to train and develop knowledge and functional skills of information technology (IT) since it increases employees' efficiency, decreases human errors, increases work pace, and consistency between operational results of the organization with the considered results and leads to the achievement of organizational goals. Hassanzadeh et al. (2008) indicated a significant relationship between role clarity and psychological empowerment of employees. The correlation coefficient was 0.72 in 
their study ${ }^{19}$. In the present research, the correlation coefficient was 0.49 between two efficiency and role clarity variables among the whole Ministry of Health staff.

\section{CONCLUSION}

Regarding the results obtained from the present research, it can be concluded that role clarity has a direct and significant relationship with Ministry of Health staff's efficiency. In means that if role clarity increases, employees' efficiency increases and if role clarity decreases, their efficiency decreases too. Therefore, the exact formulation of job description for staff, clarifying the relationship between goals and performances of the organization, staff's access to the latest required information to fulfill the tasks assigned to them and determining the responsibilities of Ministry of Health staff seem necessary for increasing employees' role clarity and efficiency.

\section{The Researcher's Suggestions}

In order to apply and utilize useful effects and results of role clarity, it is suggested that managers working for Management \& Resources Development Department of the Ministry of Health and Medical Education of I.R.Iran. do their best to increase levels of role clarity through predicting and comprehensive planning for creating and developing role clarity in formulating human resources strategies since it paves the way for more staff's efficiency. Furthermore, the following cases are recommended for increasing staff's efficiency:

1) Creating role clarity and exact formulating of job description and staff's responsibilities description and clarifying the relationship between organizational goals and performances

2) improvement and development of work processes, providing up to date tools and equipment necessary for improving staff's working conditions, and forming training workshops for suitable use of equipment and facilities

3) recognizing weaknesses and strengths of staff in performing tasks and need assessment process, prioritizing needs, planning, designing and implementing the on-the-job training courses to improve the quality and quantity of staff's work

4) Turning the organization to a knowledgeoriented organization through on-the-job training, and improving abilities and learning process, improving administrative culture,

5) Developing a performance structure suitable with the aim of attracting more contribution and cooperation from different levels of management in self-assessment process and creating incentives, support, orientation and the leader's approval for introducing and implementing self-assessment.

\section{REFERENCES}

1. Smithson, J. \& Stokoe, E.H., Discourses of work-life balance: Negotiating ,genderblind, terms in organisations, Gender, Work and Organisation, 2005; 12(2): 147-168.

2. Ghorbani, Rahim; Nafari, Neda; Rezaei, Simin The relationship between role clarity and job commitment of the clerks of Agriculture Bank / Tehran Branches. Public Management, 2012; 4(9); 83-98

3. Becker TE, Klimoski RJ., A field study of the relationship between the organizational feedback environment and performance at sport. Personnel Psychology; 1989; 42(2): 343-58.

4. Jackson, S.E and Schuler, R.S., A meta-analysis and conceptual critique of research on role ambiguity and role conflict in work-settings, Organisational behaviour and human decision Process, 1985; 36: 16-78.

5. Tubre, T. C., \& Collins, J. M., Jackson and Schuler (1985). revisited: a meta-analysis of the relationships between role ambiguity, role conflict and job performance. Journal of Management, 2000; 26: 155-169.

6. Abramis D.J., Work role ambiguity, job satisfaction, and job performance: Metaanalyses and review. Psychological Reports; 1994; 75(3): 1411-33.

7. Blumenthal, S., Lavender, T., \& Hewson, S., Role clarity, perception of the organization and burnout amongst support workers in residential homes for people with intellectual disability: A comparison between a national health service trust and a charitable company. Journal of Intellectual Disability Research, 2001; 42: 409417.

8. Kahn, R.L, Wolf, D.M, Quinn. R.P, Snoek, J.D \& Rosenthal, R.A., Occupational stress: Studies in role conflict and ambiguity. New York: Willey, 
1964.

9. Spreitzer, G. M., Kizilos, M. A. and Nason, S. W., A dimensional analysis of the relationship between psychological empowerment and effectiveness, satisfaction, and strain. Journal of Management, 1997; 23: 679Ú696.

10. Robert, D., Role clarification program: detailes methodology. Available from web:http:// www.uai-ropes.com/role-clarification-programdetail.html, 2003.

11. Blau, G.J, et. al., Job commitment and organizational commitment as interactive predictors of tardiness and absenteeism, Journal of Management, 1993; 12: 577-584.

12. Sawyer, J. E., Goal and process clarity: Specification of multiple constructs of role ambiguity and a structural equation model of their antecedents and consequences. Journal of Applied Psychology 1992; 77: 130-142.

13. Kontodimopoulos N, Panagiotis N, Dimitris N., Balancing efficiency of health services and equity of access in remote areas in Greece. Health Policy; 2006; 76: 49-57.

14. Irannejad, Parizi, Mehdi; Sasangohar, Parviz., Orgaznaition and Management, From Theory to Practice. 11th Edition. Tehran: Iran Banking Studies Institute, Central Bank of the Islamic Republic of Iran. 2011; 8-9

15. Rezaeian, Ali., Fundamentals of Organizational Behavior Management. Tehran: SAMT Publications. 2003; 27

16. Kauppila, O. P., So, What Am I Supposed to Do? A multilevel examination of role clarity. Journal of Management Studies, 2014; 51: 737 763.

17. Hassan, S., The importance of role clarification in workgroups: Effects on perceived role clarity, Work satisfaction, and turnover rates. Public administration review, 2013; 73: 716-725.

18. Furenes, May Irene; Furenes, Trond., The effect of service employees. perception of role clarity and psychological empowerment on organizational commitment, job satisfaction and staying intention, University of Stavanger, Norway, http://idtjeneste.nb.no/URN:NBN:nobibsys_brage_25768http://hdl.handle.net/ 11250/185139, 2011.

19. Hassanzadeh, Abdolmajid; Rajaeipour, Saeid; Noori, Abolghasem., Role Clarity and Psychological Empowerment. Public Management Viewpoint. 2013; 14: 135-155

20. Rajaeipour, Hassan; Bahrami, Susan., The relationship between role clarity and job commitment of the employees of the schools of Isfahan University of Medical Sciences.
Shahrekord University of Medical Sciences Journal. 2008; 10(2). pp. 30-36

21. Mukherjee, A., \& Malhotra, N., Does role clarity explain employee-perceived service quality? A study of antecedents and consequencesin call centres. International Journal of Service Industry Management , 2006; 17(5): 444-473.

22. Klein, H.J., The effects of early socialization experiences on content mastery and outcomes: A meditational approach. Journal of Vocational Behavior. 2006; 68(5): 69

23. Lyons.T.F. (2004). Role clarity, need for clarity,satisfaction, tention, and Withdrawal and work- retated variables, Journal of Applied Psychology.85(5):4-5

24. Bray, S. R., \& Brawley, L. R., Role efficacy, role clarity, and role performance effectiveness. Small Group Research, 2002; 33: 233-253.

25. Mcenrue M.P). (Perceived competence as a moderator of the relationship between role clarityand job performance: a test of two hypotheses. J Organ Behavi Hum Perform. 1984; 34(3) 379-86.

26. Paslari, P,Bagheri , M., b .Study of Intellectual Capital and it's relation with efficiency of organization employee (Case Study of Melli Bank Branches in Bandar Abbass) Islamic Azad University, Bandar Abbas Branch, Iran Available online at www.behaviorsciences.com Reef Resources Assessment and Management Technical Paper ISSN: 1607-7393 RRAMT 2014; 40: 2014.

27. Bagherpour, Morteza; Koohestani, Hossein; Karshekani, Hossein., An investigation of relationship of the work life quality and the efficiency of the Employees of Education Department. M.A. Thesis, Faculty of Psychology \& Educational Science, Ferdowsi University of Mashhad, http://irandoc.ac.ir, 2012.

28. Jafari, Masoumeh; Eivazadeh, Esmaeil; Moeinian, Davood., The effects of the efficiency of the managers on the level of the stress of the employees of Islamic Azad University / East Tehran Branch. Social Research Seasonal, 4th Year, 2011; 10: 165-155

29. Azadvari, Mina., Investigation of the Level of Efficieny of the Women's Police Department of Mashahd from the point of view of the Employees of Police Commandership of Mashhad. Feamle Police, 4th Year, Vol. 13. http:/ /www.sid.ir, 2010.

30. Singer M.G., Human resource management.USA: PWS-Kent publishing company; 1990; 110-5.

31 .Law approved Islamic Consultative Assembly 
the Ministry of Health., Availabl at: www.bums.ac.ir/shares/manager/manager/ hoghoghi/.../gh-90-06.doc, 2011.

32. Healy W.J., Counselor's perceptions of individual response and adjustment to job changes at sport of organization: The influence of self-esteem locus of control and dissonance. [Thesis]. Madison, US: Fairleigh Dickinson University, 1983.
33. Laudon, K. \& Laudon, J., Management information systems: organization and technology in the networked enterprise. Translated by Hamid Mohseni: Ketabdar Publications, 2000.

34. Sibley, E. H., The impact of database technology on business systems, information processing. Proceedings of IFIP Congress 77, ed. Bruce Gilchrist, North-Holland, New York, 1977; 589596. 